\title{
IDENTIFICATION OF HAZARDS IN THE WORKPLACES OF ARTISANAL MINING IN KATANGA
}

\author{
MYRIAM M. ELENGE and CHRISTOPHE DE BROUWER \\ Université Libre de Bruxelles, Brussels, Belgium \\ Unit of Occupational Health and Environmental Toxicology, School of Public Health
}

\begin{abstract}
Objective: While artisanal mining takes place in casual framework and with total ignorance of good practices, few studies have focused on the origin of hazards specific to each workplace constitutive of this exploitation facility. Nevertheless, this study is a condition of an efficient occupational health and safety control in this sector. Materials and Method: We took the effort to identify different workplaces, as well as hazards specific to each of them, through the observation and analysis of the tasks, tools and the processes related to their use applied in the Ruashi artisanal mine. Results: The investigated exploitation facility consists of five workplaces: diggers ( $60 \%$ - in charge of mineralized gangue recovery); crushers; washers; hand-made furnace workers (in charge of various treatment processes); and loaders (in charge of packing the obtained material). Beside the risks common to these various workplaces and ensuing notably from the lack of hygiene and working in bad positions, operating in underground galleries, in particular, exposes diggers to the risks connected with collapsing parts of the mine, suffocation, dehydration or fine particles in the breathed air. Crushers are especially exposed to traumatism risks, notably ocular, and loaders are exposed to risks related to handling heavy loads. These risks are connected with the mining processes because, in spite of the similarity of tools, they appear less often in other forms of artisanal exploitation described in literature. It is notable in the case of crushing in sawed gas bottles where ocular trauma risk is decreased. It was also shown that humidification of work surface reduces dust particles emission into the air. Conclusions: Hazards identification, through a tools and processes description, has the advantage of providing information on reducing the occurrence of these risks. It shows that this reduction is not necessarily a consequence of the activity mechanization degree.
\end{abstract}

Key words:

Artisanal mining, Risk factor, Risk analysis, Occupational health, Katanga

\section{INTRODUCTION}

When industrial mining fell down in the Copperbelt Province of Katanga [1], artisanal mining became the main job provider [2]. The casual framework in which this craftsmanship operates raises serious concerns about the prevention of accidents and protection of the well-being of these mining craftsmen [3].

Since hazards identification and assessment are the first steps of any strategy of risks control, the present survey aims to point out these hazards through the mining processes description [4], in order to allow building of prevention strategies that closely fit the mining processes specificity of small-scale mining in Katanga.

\section{MATHERIAL AND METHODS}

Our survey was performed on the Ruashi mining site, also called "Star Mine", located about $10 \mathrm{~km}$ from the city of Lubumbashi. The estimated ore reserve in this area equals about 2156250 tons of copper (sulfurous ore containing about $3.5 \%$ of copper) [5], 287500 tons of cobalt $(0.4 \%$ content), as well as unknown quantities

Received: June 25, 2010. Accepted: August 18, 2010.

Address reprint request to M.M. Elenge, Unite de Sante au Travail et de Toxicologie du Milieu, Ecole de Sante Publique, Cp 593, 808 Route de Lennik, 1070m Bruxelles, Belgique (e-mail: melengem@ulb.ac.be). 
of other ores such as uranium, germanium, etc. During our investigation period, this mine was not in operation and the owner of the mining rights, namely the Ruashi Mining Corporation, tolerated this artisanal mining activity because it merely affected the top layer, and a poorly mineralized oxidized layer reaching down for less than $10 \mathrm{~m}$ from the surface.

Our sampled population (systematic random sampling $\mathrm{n}=100$ ) consisted of mining craftsmen whose total headcount amounted to 1014 individuals. Our target population were all mining craftsmen of the Katanga Copperbelt region. In order to take part in the survey, each candidate had to fulfill 5 conditions, namely he had to: be a mining craftsman, have worked for over 12 calendar months at this Ruashi mine, be registered on the local census, not to have worked in an industrial mine, and agree to take part in the survey.

We conducted direct observations of non-industrial mining in order to analyze the hazards of this activity. Apart from this observation, because our survey aimed to outline the impact of the working conditions on the health of these mining craftsmen, we distributed a questionnaire based on a Swedish occupational health survey questionnaire [6]. Our survey took place from 22 December 2005 to 9 January 2006.

\section{OBSERVATIONS}

\section{Description of the mining craftsmanship}

Specific workplaces

Non-industrial mining activities in this mine are performed in four forms. The first stage involves excavation in a kind of small open-pit mines with exploitable surface at the bottom of less than $4 \mathrm{~m}^{2}$. This is followed by digging underground galleries, mainly in the areas where the top oxidized layer were not stripped off industrially. The third stage is exploitation of embankments resulting from the industrial stripping of the upper layer. Finally, effluents from the decantation pools are treated, as they still contain interesting copper-cobalt concentrations, due to the poor recovery level obtained from the refining process (electrolysis in an acid solution).

A thorough examination of the working situation enabled us to identify several different workplaces presented below (Figure 1).

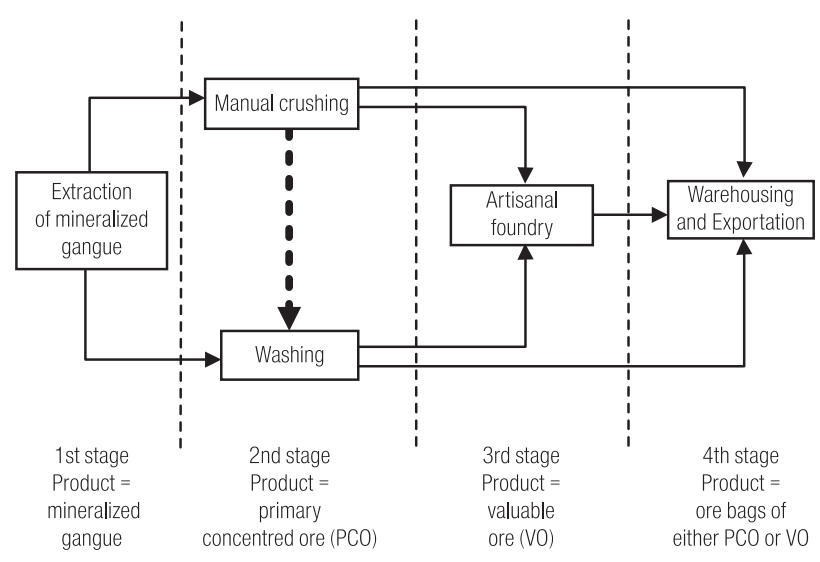

Fig. 1. Non-industrial mining cycle.

The job descriptions for each workplace may be summarized as follows:

- Digger-craftsman (60\% of our sample): responsible for digging open-pit mines or underground galleries in order to reach the mineralized gangue and carry it out after the evacuation of the sterile layer;

- Crusher: in charge of separating the crude ore from impurities contained within the extracted gangue, through crushing it with a hammer;

- Washer: in charge of the water cleaning process of the mineralized gangue or the crushed concentrate in order to improve the crude core concentration;

- Loader: responsible for packing, handling and storage of the finished product, including loading it onto vehicles for export;

- Hand-made furnace worker: in charge of further product refining through pyrometallurgy in order to 
separate the crude ore from the remaining impurities with the use of gravity.

Operating methods and techniques of each workplace

The description of effective means regarding various operating phases, whether legal or illegal, enables us to outline the hazards specific to each workplace.

\section{The mineralized gangue recovery phase}

All diggers reported using an equipment consisting of hand tools for drilling and digging (pickaxes, shovels, crowbars, pikes). The rate of lighting equipment use (93.43\% for battery-powered electric lamps) shows that all of them work in a poorly-lit environment (in galleries or during night shifts). Most of the diggers also use a sieve. Prior to the exploitation phase, a site prospection takes place. It starts with searching for mineralization signs, i.e.: observers whose presence on the ground level increases the possibility of finding well-mineralized layers underground. Based on the discovered signs, several shafts, covering a given area, are dug down to reach the mineralized layer. Depending on the thickness of the mineralized gangue found in the individual shafts, an assessment of the shape and orientation of the seam is made; its volume is also assessed. These shafts are made with the use of shovels with shortened handles for better handiness whose maximal diameter equals $80 \mathrm{~cm}$. Several diggers work in turns, removing the sterile in small vessels drawn with ropes, sometimes using also rudimentary pulleys.

When the shafts reach the groundwater level, water is removed through the same vessels as in the case of sterile. Sometimes, diggers who can afford it, rent motor-pumps; but it is rather rare during the prospecting phase. This phase ends up with the yield assessment of the extracted mineralized gravel, leading to mine exploitation or shafts abandonment.

The regulations stating what is to be done prior to digging an excavation, e.g., how to pull out trees and plants in order to reduce the environmental impact, are neither known nor observed by the diggers.

On the other hand, since artisanal mining is authorized only within delimited areas which are usually poorly mineralized, diggers prefer to work within industrial perimeters where mineralization is well-known, sometimes with the owner's acceptance who, in return, gets exclusive rights to buy the raw material obtained due to their work [7, p. 376]. Therefore, the main issue related to prospection is connected with finding the level with the highest possible mineralization, as the estimates of reserves are mostly related to very deep industrial mines.

Various exploitation techniques are used, depending on the availability of resources and on the mineralization yield, which involves either drilling underground galleries, or digging a large opening. The first option, which is formally prohibited [8], requires the most limited number of resources and means following the richest veins. In practice, several galleries are drilled from one or more shafts in various directions following the highest concentrations. Sometimes, they are interspersed with higher areas (square-shaped) called "salons" where diggers can stand up. The workers go down, each with his own rope, with which they communicate with their colleagues on the ground level, by means of a code based on rope pulling. They work in turns lasting about two hours.

In these galleries, diggers use torch lamps and candles. The temperature is very high. If there occurs a problem concerning water removal, a motor pump is sometimes rented and placed at the entrance of the gallery in such a way that its flexible hose goes down to the water point. The water pumped out of the gallery is used for washing purposes. Once again, mineralized gangue is removed from the galleries in small vessels pulled out with ropes. The second option, namely digging openings, is not conducted in a legally approved way, either. Although the regulations require an open-pipe mine with the maximum inclination of $15^{\circ}$, a steps band with the minimum width 
of $1 \mathrm{~m}$ and the maximum depth of $2 \mathrm{~m}$ [9] in order to reduce collapse hazards, artisanal diggers always make more extensive excavations called " $4 \times 4$ " because they are made so as to allow an exploitation area of $4 \mathrm{~m}$ by $4 \mathrm{~m}$. Since diggers remain underground without any resources during the whole excavation operation, this period must be as short as possible and an open-pipe mine made according to the official regulations would take much more time.

For the purpose of excavation digging, crowbars are used to eliminate obstacles such as big stones (no explosives used), and manual scouring is made with shovels and pickaxes until the mineralized layer is reached.

Generally, the depth of the excavations does not exceed $20 \mathrm{~m}$. The regulations allow a maximum depth of $30 \mathrm{~m}$ but, usually, after $15 \mathrm{~m}$, the ground becomes so rocky that digging becomes very laborious. The excavations are shaped in a steep slope with plateaus on one side wall, to be used as steps for access and removal of the product. The plateaus are located on the side of the lowest concentration. As the exploitation goes on, diggers sometimes progressively pull down other side walls in order to follow richer veins. However, at other times, instead of pulling down the entire façade, they drill horizontal holes. Nevertheless, the excavations remain limited to sites where the mineralized layer appears at relatively small depths (10 to $15 \mathrm{~m}$ ). Actually, in case of greater depths, steep slopes present too great collapsing hazards and the multiplication of plateaus requires more resources and longer excavation time. In these cases, diggers generally prefer drilling galleries, even if this is prohibited.

Sterile removal from these hand-made excavations is conducted with shovels, step by step, as the digger who is at the lowest level sends the material up to the next plateau, and then the procedure is repeated on and on up to the ground level. The backfill is piled up near the excavation. The mineralized rocks are removed in raffia bags. Exploitation of backfills left behind by Gecamines Company is a particular case. These backfills contain several mineralization pockets with interesting concentration rates. They ensure the benefit of avoiding deep digging for miners, but on the other hand, prospection is no longer possible (no more observers). Exploitation of these mineralization pockets is performed through digging horizontal holes forming a kind of caves without any supporting structure at the opening.

\section{The mineralized gangue treatment phase}

Three concentration processes are used to extract a saleable concentrate from the mineralized gangue: manual crushing, water washing and hand-made furnaces. Only the two first processes will be discussed, as the third one takes place off the mine site and no miner from our sample is involved in it. We regrouped these crushers and washers under the name of non-diggers $(n=39)$.

\section{Manual crushing}

All crushers in our sample said they use hammers and torch lamps; about $80 \%$ of them use ropes, sieves, shovels bags and crowbars. Only $60 \%$ of them use picks. Only one of them uses a dust-proof mask.

Crushers work on the ground in a sitting position, either with their legs stretched out or bent with knees upwards and the body bending forward. Crushing is done on a hard stone with several hammer hits to separate the ore from impurities: the crusher holds the mineralized rock in place with his fingers and hits it with the hammer. To sort out the ore from impurities, crushers use a torch lamp casting light on the components of the crushed mixture. The crushed mixture is sometimes sieved in order to remove dust.

The crude ore obtained from this crushing process, when it does not undergo a consecutive washing phase, is either sent to artisanal foundry, or stored in bags and sold for export. After crushing, the heterogenite rate in the ore usually increases from less than $5 \%$ to about $20 \%$, which improves the price per kilogram. 


\section{Washing}

All washers declared that they used sieves and bags and some of them (59\%) — who also work as diggers — obviously use digging tools.

Washing is done with sieves, in artificial pools installed near the excavation sites and filled with water removed from the mine or drawn from nearby streams or rivers. However, sometimes, it is conducted in streams or rivers, even though it is strictly forbidden. During this operation, washers have their legs in water up to the knee, and bend forward to operate the immersed sieve at the knee level. The mineralized gravel is loaded progressively into the sieves that are from 50 to $70 \mathrm{~cm}$ wide, $1 \mathrm{~m}$ or more long, and from 10 to $15 \mathrm{~cm}$ deep. These sieves are operated by two washers who shake them to and fro and keep them under water deep enough so that the water hits the gravel, separating the ore from impurities (the gravel is added to the sieves with shovels, as the impurities are evacuated in a slurry form through the bottom of the sieve). When the quantity of the crude ore in the sieve allows no more addition of gravel, the sieve is removed from the water and its contents is poured into the packing bags.

\section{The phase of storage and dispatching the product}

Our sample counted 10 loaders. All of them said they used bags, shovels and sieves. Five of them use torch lamps, four use ropes, and one uses a dust mask.

The storage of the product obtained from washing or crushing is done in bags of approximately $50 \mathrm{~kg}$, near the mines. These bags are handled by loaders called "kwanda", which means a dromedary. They carry these bags on their shoulders, bending down to lift them on their own in order to place them on their shoulders. The bags are placed on the trucks at about man-height level. Sometimes handling is done in line with other persons lifting the bags and placing them on the loaders' shoulders (up to two $50 \mathrm{~kg}$ bags per loader) so that the loaders just have to bent down to put the bags into the trucks.

\section{Hazards generated by the craftsmanship-mining context}

Apart from specific hazards which can be analyzed for each workstation depending on the tools and protection means used, general hazards inherent to the occupational environment and having a heavy impact on the whole situation must be considered.

Hazards generated by the occupational environment The first category of hazards results from the lack of individual protection means, adequate working clothes and also the lack of drinkable water points and sanitary facilities near the work sites. These circumstances potentiate contamination risks as the exploitation puts craftsmen in contact with chemical components of the mineralized gangue in which the following chemicals can be found: copper, cobalt, lead, uranium, but also silica and arsenic [10].

Several contamination ways should be considered. First, cutaneous risk linked to exposure to arsenic contained in the gangue handled and contact with residual chemicals when handling effluents from decanting pools. There are also inhalation or ingestion hazards related to chemical components and radon. Finally, there are suffocation hazards due to the lack of ventilation systems, particularly in galleries or caves.

The second category of hazards related to the occupational environment results from the lack of hygiene facilities. Makeshift camps erected around the exploitation sites have neither sanitary facilities, nor adapted eating rooms, which generates contamination risks through ingestion (dirty hands diseases, diseases caused by the consumption of non-drinkable water and the use of contaminated water). There are no restrooms or cloakrooms, which leads to the possibility of contamination exchange between the workplace and the dwelling place.

Small-scale mining has all the characteristics of a job executed by independent, but strongly competing teams, because of the absence of the exclusive rights on any perimeter. Such 
situation results in intense rivalry related to the exploitation of the richest spots. That is why, the miners resort to using even the most expediting ways leading to greater hazards connected with the working conditions.

Hazards specific to different workplaces

\section{Hazards and protection means for diggers}

The description presented above shows that diggers work in an environment characterized by:

- The presence of dust and fine particles suspended in the air resulting from digging activities generating increased hazards of lung disease; in the previous survey [11], we outlined the high number of miners complaining about respiratory problems such as cough. Indeed, in comparison to the general population and after adjustment it was shown that the Odds Ratio for cough equaled 8.09 (1.86-35.25), and a deeper analysis of mining craftsmen showed a higher frequency of this symptom occurring among diggers $(17.5 \%)$ than among non-diggers (10.2\%).

- Working in mud and slurry, particularly when dealing with water removal operations.

- Working in the dark in underground galleries lit by electric torch-lamps fed by electric batteries and sometimes candles and oil lamps. This affects eyes and causes headaches. Indeed, the Odds Ratio for headaches in case of the mining craftsmen, comparing to the general population, was 5.34 (2.96-9.77) and its frequency among diggers was very high: $80.3 \%$ versus $44.7 \%$ for non-diggers.

- Poor ventilation, particularly in underground galleries when candles and oil lamps are used, or when the motor pumps used for water removal are placed inside the galleries, which increases the hazard of suffocation, previously experienced in these conditions.

- Exposure to very high temperatures - either in underground galleries or open-pit mines, generating hazards of dehydration or sunstroke.
- Drilling the galleries or caves in the back fills without any supporting structures, or steep slope excavations with horizontal holes drilled in side walls often generate serious hazards of collapse.

- Working positions, particularly during the prospection phase and working inside the galleries, generate muscle and bone troubles. For instance, comparing to the general population, the Odds Ratio for low back pain among artisanal miners was 46.28 (15.56137.66), after adjustment, and its frequency among diggers equaled $76.7 \%$ [12].

- Exposure to chemicals, particularly from the decantation pools, leading to chemical contamination hazards. The protection means used by the diggers to face those hazards are often derisory.

As far as equipment is concerned, we noticed that artisanal miners do not have any proper working clothes they use their old clothes at work.

A severe lack of individual and collective protection means can be observed (no boots, gloves or dust masks, no ventilation systems for underground galleries). As for the exploitation techniques which might compensate for poor protection means, we noticed that duty turn times in the galleries are not shortened to allow more frequent rest times in the open air. In underground galleries (this is a practice prohibited by law), the collapse prevention system based on the rope-pulling communication between the teams located outside the mine and underground is not efficient either, particularly in case of long galleries. The sustaining structures do not seem to be used anywhere.

The inadequacy of such protection means may potentiate the health problems related to the hazards the diggercraftsmen are exposed to.

\section{Hazards and protection means of non-diggers}

We grouped 49 other artisanal miners comprised in our sample in a new category named non-diggers to highlight the differences, if any, between them and the diggers $(n=61)$. 
1. Hazards and protection means for crushers

Hazards related to crushing are generated by a bad working position, projections of small stone fragments that may cause eye trauma and the fact that the workers' fingers are exposed to hammer hits. Apart from that, permanent noise caused by hammer hits may result in auditive problems and the presence of fine dust suspended in the air may cause pulmonary diseases. No protection means are used against these hazards, i.e., safety goggles, protective gloves, workstation allowing crushing in an upright or sitting position.

\section{Hazards and protection means for washers}

Washing is a job performed in mud, with bare feet (no boots), without gloves and under the influence of sunshine (quick dehydration of washing workers).

There also occur important hazards concerning muscles and bones due to a bad working position, skin hazards due to permanent immersion of a part of the body in muddy water, risk of contracting various parasitical diseases or helminthiases [13], and hazards regarding water-related diseases resulting from drinking water from rivers which refuel the washing pools.

\section{Hazards and protection means for loaders}

Handling heavy loads is essentially a physical and manual activity; no specific equipment is used for lifting or displacing the bags. Therefore, this activity is an essential factor of muscle and bone problems, notwithstanding possible accidents due to inadequate handling. No protection means or techniques, such as the use of trolleys or wheelbarrows, are used.

Comparing to diggers, non-diggers [14] present rather the same level of musculoskeletal disorders: $63.9 \%$ of them complain about low back pain, $26.5 \%$ about lower limbs pain, but only $8.6 \%$ complain about upper limbs pain, versus $18.3 \%$ of diggers $(P=0.195)$. However, $5.7 \%$ of nondiggers complain about cutaneous symptoms, versus $1.7 \%$ among diggers. This difference seems to be a consequence of the permanent body immersion in muddy water experienced by non-diggers (the symptoms of skin desquamation are also higher among non-diggers than diggers, even if this is not statistically significant). On the other hand, while no washer complained about respiratory problems, its frequency was higher among crushers than among diggers.

\section{DISCUSSION}

Few publications describe the activity conducted in artisanal mining in order to distinctly identify the workplaces that compose it, as well as the inherent hazards connected with each of them as a result of the tools and the mining processes they use.

As regards small-scale mining in Katanga, other classifications of mining craftsmen are advanced. Jan Gorus [15], for instance, divides these craftsmen into diggers, 'salizers', and warehousemen or 'kwanda'. He subdivides the first category, namely the diggers, into 'hammers' (in charge of digging galleries), 'blimps' (responsible for installing candles in the galleries or in the slaughtering) and 'drawers' (in charge of tools transportation as well as placing the crowbar at the exact place where the 'hammers' should attack the mine). According to us, this categorization is too detailed and does not correspond to the results of our questionnaire because it would suggest, for example, that some mining craftsmen (the blimps) have no tools apart from candles. Yet, we did not encounter any mining craftsman who would declare that he used candles only or mine bars only.

The SAESSCAM, an administrative service in charge of training diggers, uses a census form that categorizes these craftsmen in diggers, drawers, sorters, shippers, etc. [16]. Contrary to Jan Gorus, the SAESSCAM considers drawers to form a specific category, different from diggers. Nevertheless, our remark concerning weak differentiation of tasks covered by this classification remains valid. 
It is generally accepted that the key factors to be taken into account while preparing a classification of mining craftsmen must comprise tools and job descriptions, rather than the qualifiers used in the occupational environment. Only such approach makes it possible to describe better the real content of each job, the mining processes related to it and, therefore, also particular hazards to which each category of craftsmen is exposed.

With the support of the Mining, Minerals and Sustainable Development project, several studies were undertaken on small-scale mining in various African countries. Some of them put special emphasis on the tools, techniques and mining methods. In his description of methods and mining processes of artisanal mines in Mali, Seydou Keita [17] enumerates among the tools used there shovels, peaks, pickaxes, water-bottles as well as motor-driven pumps for unwatering. He also points out that the digging technique consists in squaring a given perimeter by a few small vertical wells, from which several galleries are dug, once the mineral-bearing layer is reached. This technique corresponds to the one described by us, regarding the underground galleries in the site of Ruashi. He also emphasizes that these galleries are sometimes several hundred meters long. This length obviously exceeds that of the galleries created by the artisanal diggers in Katanga. This difference can be explained by different nature of the soil, as Katanga's sites are argillaceous and very close to ground water.

As for the treatment of the mineralized gravel, Seydou Keita also speaks about manual crushing (quartzose ore containing gold) in workshops saturated with silica dust. In such case, crushing is done in sawed gas bottles, in which ramming is conducted with an iron bar, before the gravel lamination on millstones of stone takes place. This concentration technique is therefore different from what we described and undoubtedly has the advantage of reducing ocular traumatism hazards, due to the projection of glares during hammer crushing. Such proximity of techniques and mining methods suggests that artisanal miners, in these various countries, transposed to mining art traditional techniques, probably more adapted to other forms of activity. Thus, such maladjustment not only leads to very low recovery levels of the exploited ore, but also to important health problems, because of the hazards that are not taken into account.

Indeed, it was also noted by Gibril Gueye [18] who describes the methods and mining processes in Burkina Faso and stresses the use of vertical wells from where the galleries take their beginning. He also reported the use of tools such as hammers, pickaxes, jumper bars, and shovels, scales made of wood or string, buckets, water-bottles, plastic bags or bags of jute, etc. The ore treatment is done by crushing in metal mortars, and it is followed by sifting (with the use of wooden sieves). Although the working positions during these various operations are not described, we can assume that these movements are the same and that they are carried out under the same conditions and, consequently, they expose the workers to the same hazards. Such similarity of tools and methods also emerges from descriptions of the artisanal mining processes in Southern Africa [19].

As for the hazards encountered in these types of exploitation, the results of our research support the conclusions of other authors who made investigations in the same research area. In his study on occupational problems in small-scale mining, Norman Jennings (1999) noted that the level of hazards was not the same in the opencast mines as in the case of the underground ones [20]. While listing these hazards, he reports that, in opencast mines, the presence of fine particles in the air is caused by digging operations, crushing of rough ore and even loading. He also underlines that this exposure to dust involves respiratory problems, and in particular silicosis [21]. This observation of the importance of hazards arising from exposure to dust is also noted by Thomas Hentschel et al. (2002), who, in a review of the artisanal and small-scale mining 
activities in several countries, gave a progress report on the health and safety issues in these exploitation sites. Moreover, they put emphasis on the problems occurring due to the absence of ventilation [22].

\section{CONCLUSION AND RECOMMENDATIONS}

Taking into account the tools used by the mining craftsmen and the implemented working processes, we could categorize the small-scale mining workplaces in a way that allowed us to highlight the specific hazards of each of these workplaces, as well as the general hazards concerning the whole profession. This hazards analysis enabled us to outline the variety and range of risks that craftsmen-miners are exposed to, due to the informal character of their activities, disrespect for mining best practices, and insufficiency and inadequacy (if not total lack) of the protection means used. These various hazards expose miners to known health problems such as muscle and bone diseases, illnesses generated by water, working accidents (gallery collapse), poisonings, etc. In spite of the common use of similar tools, we also noted that some mining processes are specific to Katanga small-scale mining and are not met in descriptions of other types of exploitation. That suggests that a strategy of risks prevention in this area must be worked out around the specificity of the tools and technology used, even if, at the end, the hazards are the same: inhalation of fine dust in the air, traumatism, crumbling, etc. These various risks, although they are more present in certain countries than in others, seem nevertheless more connected with the nature of the artisanal mining activity than with the level of poverty of people involved in it or the ineffectiveness of administrative controls. Indeed, as we underlined in our previous study on the adequacy of artisanal mining legislation on exploitation constraints, the same failures are observed in all countries where artisanal mining prospers [7, p. 387]. The only real possibility of fighting against these practices is introducing a minimum of mechanization and modernization into these mines [23].The important contribution of this sector to the national economic situation should motivate the public authorities to support actions aiming at ensuring health, wellbeing and protection of this population, especially because many of such measures do not require important financial efforts [24].

\section{REFERENCES}

1. Hocquard C. Informalization of mining activities in the Democratic Republic of Congo. [cited: 2003 Oct 1]. Available from: http:// www.mineralinfo.org/Lettres/L2003/L0307.html [in French].

2. COPIREP. Proceedings form the workshop training on small scale mining in Katanga. 22-23 June 2004, Lubumbashi, Congo [in French]. Available from: http://www. copirep.org/documents/rapports/s\%E9minaire\%20sur\%20 1\%27exploitation\%20mini\%E8re\%20au\%20Katanga.pdf.

3. Global Witness. Rush and ruin, The devastating mineral trade in southern Katanga, DRC [report]. London: Global Witness; 29 September 2004.

4. Institut de Veille Sanitaire. Guidelines for medical aspects of environmental impact survey. Saint-Maurice: InVS ; 2000 [in French].

5. Okitaudji LR. A genetic model of Shaba copper-cobalt mines series, Democratic Republic of Congo. Bull Acad Lorr Sci 2001:40-4 [in French].

6. Lundberg I, Hogberg M, Michelsen H, Nise G, Hogstedt C. Evaluation of the Q16 questionnaire on neurotoxic symptoms and a review of its use. Occup Environ Med 1997;54:343-50.

7. Elenge MM. Mining law, environment and occupational health protection of artisanal miners in DRC. Congo-Afrique 2008;425:373-90 [in French].

8. Guidelines in craftsmanship mining. JORDC no special of 1 April 2003. Decree no 038/2003 of 26 March 2003 related to mining regulations. Art. 3.

9. Guidelines in craftsmanship mining. JORDC no special of 1 April 2003. Decree no 038/2003 of 26 March 2003 related to mining regulations. Art. 9 . 
10. Musée Royale de l'Afrique centrale. Mineralogy Data base [cited 2005 Feb 2]. Available from: http://www.metafro. be/mineralogy.

11. Elenge MM, Aubry JC, De Brouwer C. Health impact of working conditions at the Ruashi mine in the Democratic Republic of Congo. Med Trop 2009;69:490.

12. Elenge MM. Health impact of working conditions at the Ruashi mine in the Democratic Republic of Congo [master thesis]. Université Libre de Bruxelles; 2006.

13. Jancloes MF, Cornet P. Epidemiological control of intestinal nematodoses in a rural area of Zaïre. Rev Epidemiol Sante Publique 1980;30:89-103.

14. Elenge MM. Health impact of working conditions at the Ruashi mine in the Democratic Republic of Congo [master thesis]. Université Libre de Bruxelles; 2006. p. 18.

15. Gorus J. Artisanal mining in Katanga. Brussel: Vrije Universiteit Brussel; 2006 [in French].

16. Service d'Assistance et d'Encadrement du Small Scale Mining (SAESSCAM). Artisanal Miner Identification Form. Kinshasa: Ministry of Mines; 2004 [in French].
17. Keita S. Artisanal and small scale mining in Mali [report]. MMSD 2001;80.

18. Gueye D. Artisanal and small scale mining in Burkina Faso. MMSD 2001;73

19. Dreschler B. Small Scale Mining and Sustainable Development within the SADC region [report]. MMSD 2001;84.

20. Jennings NS. Social and labour issues in small scale mining. Geneva: ILO; 1999.

21. Walle M, Jennings NS. Safety and health in small scale surface mines. A handbook. Geneva: ILO; 2001.

22. Hentschel T, Hruschka F, Priester M. Global report on artisanal and small scale mining [report]. MMSD 2002;70.

23. Dreschler B., Small-Scale mining and sustainable development within the SADC region. MMSD 2001;16.

24. Jennings NS. Improving Safety and Health in mines: A long and winding road [report]. MMSD 2001;54.

This work is available in Open Access model and licensed under a Creative Commons Attribution-NonCommercial 3.0 Poland License - http://creativecommons.org/ licenses/by-nc/3.0/pl/deed.en. 